\title{
Editorial
}

\section{Recommendations on oral lichen by GEMUB !}

\author{
Jean-Christophe Fricain ${ }^{*}$ \\ University of Bordeaux, Bordeaux, France
}

(Received: 16 November 2019, accepted: 18 November 2019)

Oral lichen is the most common pathology of the oral mucosa. Article "Lichen plan buccal : histoire naturelle et transformation maligne" by Stella Lysitsa [1] is at the top of the MBCB/JOMOS consultations with more than 20000 views and 11000 downloads, which shows the interest of oral surgeons for this complex pathology.

Complex by:

- the variety of intraoral clinical forms which includes numerous elementary lesions (keratotic papule, keratotic network, keratotic plaque, erythema, erosion, ulceration, bubble, macula),

- multiple locations: skin or the integuments (hair, nails), mucous membranes (genital, anal, esophagus, conjunctiva),

- the evolution towards other pathologies (leucoplakia like lesion, verrucous proliferative leukoplakia, verrucous carcinoma, squamous cell carcinoma),

- the overlap with other bullous diseases (pemphigoid lichen planus, chronic ulcerative stomatitis),

- the existence of lichenoid lesions more or less clinically or histologically similar to idiopathic oral lichen planus,

- the existence of lichenoid lesions induced by a systemic disease (graft versus host disease, hepatitis c, good syndrome, APECED ...),

- the existence of lichenoid lesions induced by an old drug (e.g. chloroquine) or more modern (e.g. check point inhibitor).

The multiplicity of the forms of oral lichen helps to create a "medical blur" that makes the assessment and treatment of oral lichen difficult. The first work of recommendations of the study group of the oral mucosa (GEMUB) has set its sights on this pathology to clarify the elements of the diagnostic workup. The rational of this work is the absence of French or European "robust" recommendations, on the management of oral lichen, from societies of dermatology, oral or maxillofacial surgery. In the United

\footnotetext{
*Correspondence: fricainj@aol.com
}

States, AAOMP (American Academy of Oral and Maxillofacial Pathology) has developed its own monodisciplinary recommendations [2]. However, these monodisciplinary recommendations are not based on a systematic methodology, and are not graduated. There are numerous systematic reviews of therapeutic interventions for oral lichen, including two Cochrane reviews $[3,4]$ but none of them address the initial assessment, the management of induced oral lichenoid lesions and follow-up of patients.

The originality of the GEMUB recommendations lies in the multidisciplinary approach (oral surgeons, dermatologists, stomatologists, maxillofacial surgeons, anatomopathologists). This multidisciplinary approach is essential to address a pathology as ubiquitous and polymorphic as oral lichen and to overcome the compartmentalization of medical specialties. As proof of this, the stenosing erosive esophagitis of gastroenterologists corresponds in a not insignificant number of cases to a lichen planus, pathology almost unknown in this specialty.

The recommendations were developed according to a methodology build on the formalized consensus of the HAS which guarantees the consensual and graduated nature of the recommendations. These recommendations address 4 key points related to the clinical and paraclinical assessment of oral lichen:

- the initial assessment and the nosological framework of the oral lichen: should we systematically perform a biopsy, a direct immunofluorescence, a serology of $C$ hepatitis, a periodontal and dental checkup and look for genital involvement. When to suspect a pemphigoid lichen planus? - diagnosis and management of suspected drug-induced oral lichenoid lesion,

- diagnosis and management of suspected contact-induced oral lichenoid lesions,

- the follow-up of the oral lichen: by whom, when and how?

These questions were the subject of 22 short questions/ recommendations and a long argument based on a systematic analysis of the literature. 
These recommendations will be available on the SFCO website and could be used from the first quarter of 2020. I can only encourage you to watch for their release as they will undoubtedly be of great help for the oral surgeon.

\section{References}

1. Lysitsa S, Abi Najm S, Lombardi T, Samson J. Lichen plan buccal: histoire naturelle et transformation maligne. Med Buccale Chir Buccale 2007;13:19-29.
2. Cheng YS, Gould A, Kurago Z, Fantasia J, Muller S. Diagnosis of oral lichen planus: a position paper of the American Academy of Oral and Maxillofacial Pathology. Oral Surg Med Oral Pathol Oral Radiol 2016;122:332-354.

3. Thongprasom K, Carrozzo M, Furness S, Lodi G. Intervention for oral treatment lichen planus. Cochrane Database Syst Rev 2011;7: CD001168.

4. Cheng S, Kirtschig G, Cooper S, Thornhill M, Leonardi-Bee $\mathrm{J}$, M urphy R. Intervention for erosive lichen planus affecting mucosal sites. Cochrane Database Syst Rev 2012;2: CD008092. 